\title{
Numerical methodology for evaluation the combustion and emissions characteristics on WLTP in the light duty dual-fuel diesel vehicle
}

ARTICLE INFO

Received: 13 July 2021

Revised: 21 October 2021

Accepted: 25 October 2021

Available online: 22 November 2021
The worldwide aim of reducing environmental impact from internal combustion engines bring more and more stringent emission regulations. In 2017 by EU has been adopted new harmonized test procedure called WLTP. In general terms this test was designed for determining the levels of harmful emissions and fuel consumption of traditional and hybrid cars. This procedure contains specific driving scenarios which representing reallife driving patterns. Test cycles contain vehicle velocity versus time profiles and directly in powertrain analysis on the test benches cannot be used. In order to back calculate drive cycles to engine rpm versus torque profiles a simple longitudinal vehicle dynamics method was used in this paper. Moreover, in order to determine most representative engine operation points during WLTP a density based grid clustering method was implemented. The experimental part of the study focuses on the comparative evaluation of the effect of various diesel to $L P G$ substitution ratios (0\% LPG, 10\% LPG, 20\% LPG and 30\% LPG) on combustion and emission characteristics of dual-fuel diesel engine.

Key words: dual-fuel engine, drive cycle simulation, internal combustion engine, emission reduction, alternative fuels, WLTP

This is an open access article under the CC BY license (http://creativecommons.org/licenses/BY/4.0/)

\section{Introduction}

The worldwide environmental considerations provide to increasing the stringent regulations that are aimed to lowering the harmful emissions $\left(\mathrm{HC}, \mathrm{CO}, \mathrm{PM}\right.$ and $\mathrm{NO}_{\mathrm{x}}$ ) in the exhaust gases of the internal combustion engines. In 2017 the Worldwide Harmonized Light Vehicles Test Procedure has been adopted as the new test procedure in the European type-approval system and replaces the New European Driving Cycle. While the NEDC was based on theoretical driving scenarios, the WLTP was developed using real-driving data with the aims to provide real-life driving conditions. Moreover, WLTP includes several test cycles (called WLTC) applicable to vehicle categories of different rated power to curb mass ratio. In general, WLTP driving cycles is divided into four parts with different average speeds: urban driving (low), suburban driving (medium), extraurban driving (high), and a highway zone (extra high) (Table 1). Each part contains a variety of driving phases (varying vehicle velocity within time) shown in Fig. 1.

Table 1. WLTC test cycles for conventional vehicles [17]

\begin{tabular}{|l|c|c|c|}
\hline $\begin{array}{l}\text { Vehicle } \\
\text { catego- } \\
\text { ry }\end{array}$ & PMR [W/kg] & $\begin{array}{c}\mathrm{V}_{\max } \\
{[\mathrm{km} / \mathrm{h}]}\end{array}$ & Driving phases \\
\hline 1 & $22 \leq$ PMR & - & Low + Medium + Low \\
\hline 2 & $22<$ PMR $\leq 34$ & - & $\begin{array}{c}\text { Low }+ \text { Medium }+ \text { High }+ \\
\text { Extra High }\end{array}$ \\
\hline $3 a$ & PMR $>34$ & $<120$ & $\begin{array}{c}\text { Low + Medium + High }+ \\
\text { Extra High }\end{array}$ \\
\cline { 1 - 3 } & & $\geq 120$ & $\begin{array}{c}\text { Low + Medium }+ \text { High }+ \\
\text { Extra High }\end{array}$ \\
\cline { 3 - 4 } & & & \\
\hline
\end{tabular}

Driving cycles are used to gain a quantitative understanding of fuel consumption and emissions for traditional and hybrid cars during either development phase or homologation process under specific driving scenarios. Moreover, these driving cycles allows to perform powertrain analysis during real-life driving or during investigations on the test benches. In order to use driving patterns in test bench investigations they must be back calculated from vehicle velocity versus time profiles to engine rpm vs. torque profiles. This objective can be achieved by the longitudinal vehicle dynamics approach. Longitudinal dynamics approach is a low time consumption method that makes use of as limited information as possible referring mainly to already available data sources in combination with empirical models, while allows to, provide simulation with required accuracy.
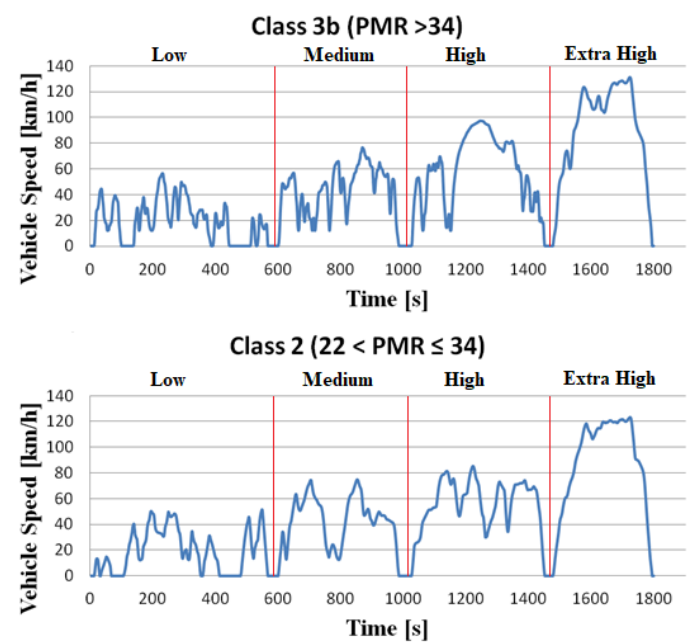

Class 1 ( $22 \leq$ PMR)

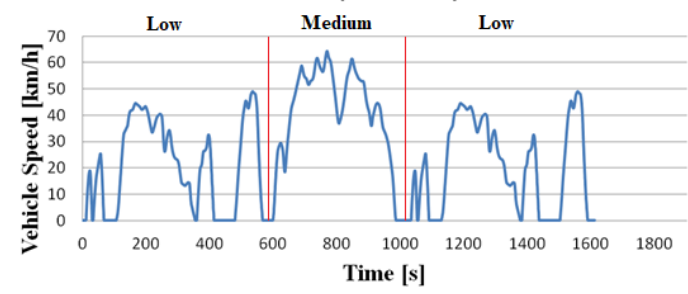

Fig. 1. Speed vs. time traces of the WLTC driving cycle for all vehicle classes [17] 
The current work presents simple longitudinal dynamics method in combination with WLTP gear-shifting rules and density based grid clustering method for assessing the introduction of Worldwide Harmonized Light Vehicles Test Procedure in the light duty dual-fuel diesel vehicle (using the example a Golf IV car). Moreover, combustion and emission characteristics of various diesel fuel to LPG substitution ratios $(0 \%$ LPG, 10\% LPG, 20\% LPG and 30\% LPG) in the most representative operation points during the WLTP are evaluated in this article.

\section{Methodology}

In this work, fuel effect on engine performance and emissions has been evaluated under Worldwide Harmonized Light Vehicles Test Procedure. In order to back calculate specific drive patterns to engine rpm and torque, was selected commercial FWD passenger vehicle Golf IV, made by Volkswagen factory, technical specifications are presented in Table 2 and Fig. 2.

Depending on the rated power to curb mass ratio of Golf IV $3 \mathrm{~b}$ test scenario (time-based profile of vehicle speed) (Fig. 1) has been selected.

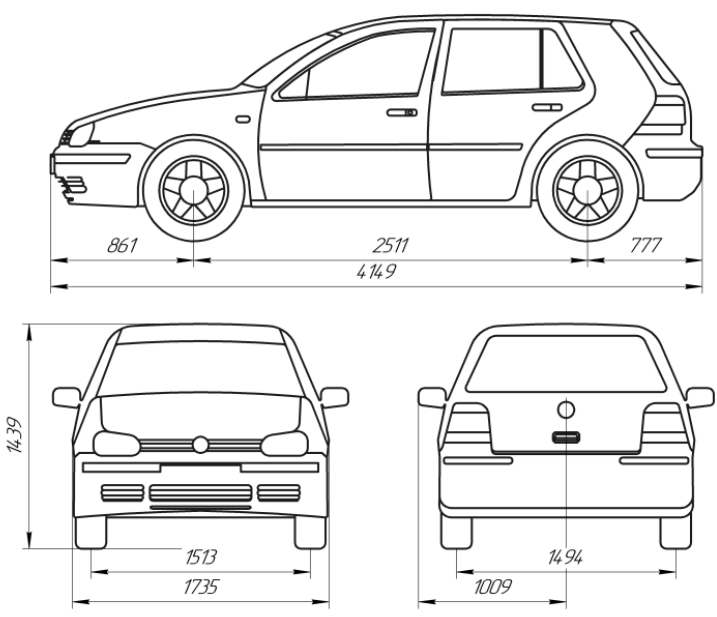

Fig. 2. Volkswagen Golf IV dimensions [19]

Table 2. Volkswagen Golf IV technical specifications [19]

\begin{tabular}{|l|c|c|}
\hline Parameter & Unit & Value \\
\hline Brand, Model \& Generation & - & Volkswagen Golf IV \\
\hline Production & year & 2000 \\
\hline Maximum speed & $\mathrm{km} / \mathrm{h}$ & 195 \\
\hline Vehicle curb weight & $\mathrm{kg}$ & 1237 \\
\hline Vehicle gross weight & $\mathrm{kg}$ & 1300 \\
\hline Vehicle total weight & $\mathrm{kg}$ & 1780 \\
\hline Tires & - & $195 / 65 \mathrm{R} 15$ \\
\hline Gearbox & - & Manual 6-Gear \\
\hline
\end{tabular}

\subsection{Longitudinal dynamic method description}

Longitudinal dynamic model implements a one degreeof-freedom rigid vehicle body with constant mass undergoing longitudinal motion. The vehicle axles are parallel and form a plane. The longitudinal direction lies in the parallel plane and is perpendicular to the axles. If the vehicle is traveling on a slope, the normal direction is not parallel to gravity but is always perpendicular to the axle-longitudinal plane (MathWorks, n.d.).

All forces acting on the vehicle during the motion shown in Fig. 3.

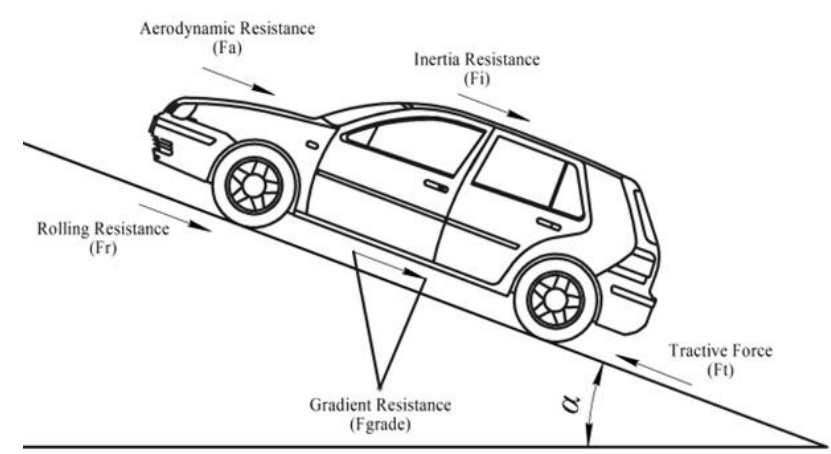

Fig. 3. Forces distribution under longitudinal motion

In general term, to ensure vehicle motion a provided torque from powertrain system on a driving wheels, must allow to obtain a force exceeding the motion resistance forces. Figure 4 illustrates a simplified version of the engine powertrain system.

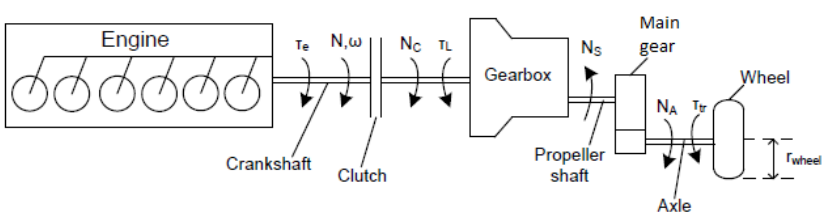

Fig. 4. Conceptual illustration of powertrain system [5]

\subsection{Powertrain analysis}

In this analysis we assume that the road surface is to be flat and vehicle will behave according to Newton's second law. The basic equation can be expressed as

$$
\sum \mathrm{Ft}=\sum \mathrm{Ftr}
$$

The powertrain model includes the various sub-modules vehicle dynamics model, wheel dynamics model and gear shifting strategy. Application of the below-described submodels is necessary so as to convert the vehicle speed vs. time profile (Fig. 1), into engine torque vs. speed profile (Fig. 7). After that, the grid clustering method followed by experimental analysis can be applied.

\subsection{Vehicle dynamics model}

The first step of the calculation is to derive all resistance forces acting on car during motion. The four resistance forces experienced by a vehicle during the motion are the aerodynamic resistance, tire rolling resistance, gradient resistance and inertia resistance. Total traction resistance is given by

$$
\sum \mathrm{Ftr}=\mathrm{Fr}+\mathrm{Fa}+\mathrm{Fi}+\text { Fgrade }
$$

\subsubsection{Aerodynamic resistance}

The component of exerted force that acts on moving object by the air in opposite direction relative to their motion called aerodynamic resistance. This resistance can be approximated as $[2,3,5,8]$ : 


$$
\mathrm{Fa}=0.5 \times \rho \times \mathrm{Cd} \times \mathrm{Af} \times \mathrm{V}^{2}
$$

where

$$
\mathrm{Af}=0.9 \times \mathrm{H} \times \mathrm{B}
$$

The aerodynamic drag coefficient varies according to the vehicle shape. The most common values for this coefficient shown in Fig. 5.

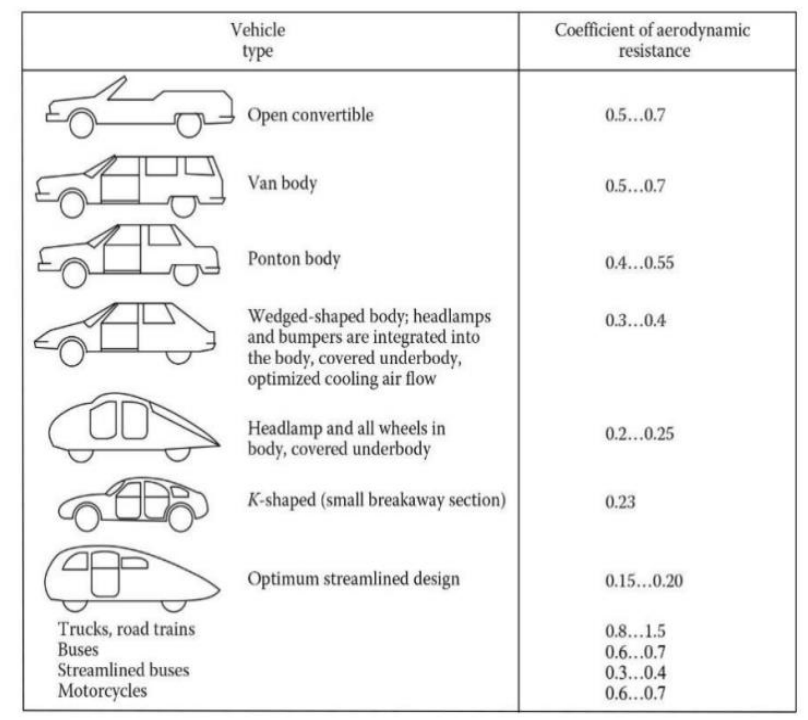

Fig. 5. Aerodynamic drag coefficient for different vehicle types [3]

\subsubsection{Tire rolling resistance}

The tire rolling resistance is a force applied to each wheel with a dynamic radius with opposite direction to the car's motion. This force is calculated from equation $(5)[2,8]$ :

$$
\mathrm{Fr}=\mathrm{m}_{\mathrm{v}} \times \mathrm{g} \times \mathrm{Crr} \times \cos \alpha
$$

The rolling resistance coefficient depends on the road surface and determined experimentally. The typical values of the rolling resistance coefficient given in Table 3.

Table 3. Rolling resistance coefficient [6]

\begin{tabular}{|c|c|}
\hline Road and pavement condition & Value \\
\hline Very good concrete & $0.008-0.01$ \\
\hline Very good tarmac & $0.01-0.0125$ \\
\hline Average concrete & $0.01-0.015$ \\
\hline Very good pavement & 0.015 \\
\hline Very good macadam & $0.013-0.016$ \\
\hline Average tarmac & 0.018 \\
\hline Concrete in poor condition & 0.02 \\
\hline
\end{tabular}

\subsubsection{Gradient resistance}

If the car moves on a sloping road, weight of the vehicle produces a component of gravitational force, which acts on the vehicle center of gravity and always directed downward. This force is usually called gradient resistance. Generally, in standard tests assumed flat road surface therefore $[5,8]$ :

$$
\text { Fgrade }=0
$$

However, gradient resistance can be calculated from this equation $[2,8]$ :

$$
\text { Fgrade }=\mathrm{m}_{\mathrm{v}} \times \mathrm{g} \times \sin \alpha
$$

\subsubsection{Inertia resistance}

During the car motion with acceleration, an inertial force is produces, which acts on the center of the vehicle mass in opposite direction to its motion. This force usually called inertia resistance and can be calculated from this equation $[2,6]$ :

$$
F i=m_{i} \times \frac{d V}{d t}
$$

\subsubsection{Vehicle inertia mass}

The inertia mass is a total mass of the vehicle increased by the mass factor $[1,7]$ :

$$
\mathrm{m}_{\mathrm{i}}=\mathrm{m}_{\mathrm{v}} \times \delta
$$

Mass factor can be approximated from the equation below $[2,8]$ :

$$
\delta=\mathrm{d}_{1}+\mathrm{d}_{2} \times \mathrm{i}_{\mathrm{g}}^{2}
$$

where

$$
\begin{gathered}
\mathrm{d}_{1}=\frac{1+\sum \mathrm{J}_{\mathrm{w}}}{\mathrm{r}_{\mathrm{d}}^{2} \times \mathrm{m}_{\mathrm{v}}} \\
\mathrm{d}_{2}=\frac{\mathrm{J}_{\mathrm{p}} \times \eta_{\mathrm{t}} \times \mathrm{i}_{0}^{2}}{\mathrm{r}_{\mathrm{d}}^{2} \times \mathrm{m}_{\mathrm{v}}}
\end{gathered}
$$

If mass moments of inertia of the rotating parts associated to the powertrain system are not known, the mass factor, for a passenger car can be estimated from the following empirical equation:

$$
\delta=1.04+0.024 \times \mathrm{i}_{\mathrm{g}}^{2}
$$

\subsection{Wheel dynamics model}

In this block as described in the equations below are calculated:

1. Wheel rotating speed from the velocity profile

$$
V=\frac{\pi \times N_{c} \times r_{d}}{30 \times i_{g} \times i_{0}}
$$

2. Tractive force, as a result of engine torque transmitted on the driven wheels, from vehicle powertrain system, as described in the equation below $[5,19,21]$

$$
\mathrm{Ft}=\frac{\mathrm{T}_{\mathrm{e}} \times \mathrm{i}_{\mathrm{g}} \times \mathrm{i}_{0} \times \eta_{\mathrm{t}}}{\mathrm{r}_{\mathrm{d}}}
$$

where

$$
r_{d}=0.97 \times(h+r)
$$

\subsection{Gearshift strategy}

In this step specific shifting points are predicted, via gear shifting strategy for vehicles with manual transmission introduced in (UNECE, 2021). WLTP gear selection algorithm taking into account the different powertrain configurations and was designed in a way to emulate the gear shifting strategy from the real-life driving. The gear shifting process influencing on powertrain inertia and engine output speed, which as a result affects on the vehicle acceleration performance and fuel consumption. Hereby, to represent real-life driving patterns proper calculation of the gear shifting sequence is an important event during the back calculation phase. In order to determine required gears and shifting points the following boundary conditions and data are needed in gear selection algorithm: 
1. Boundary conditions that shall not be less or greater (minimum and maximum engine speed, maximum rated engine power and the corresponding rated engine speed, number of forward gears, vehicle velocity limits and others).

2. Full load power curve versus engine speed profile: the engine power demand at the resulting engine speed cannot exceed the full-load output power curve of the engine.

In general term, the calculated gear in WLTP is the gear that ensure that the engine speed is lie between a defined minimum and maximum value while providing the necessary traction power with simultaneous fulfillment of additional requirements described in [17] (i.e. avoidance instabilities in gear shifting, ensuring drive ability and others).

The generated gear shifting sequence with final engine torque vs. time profile for diesel vehicle Volkswagen Golf IV illustrated in Fig. 6 and Fig. 7.

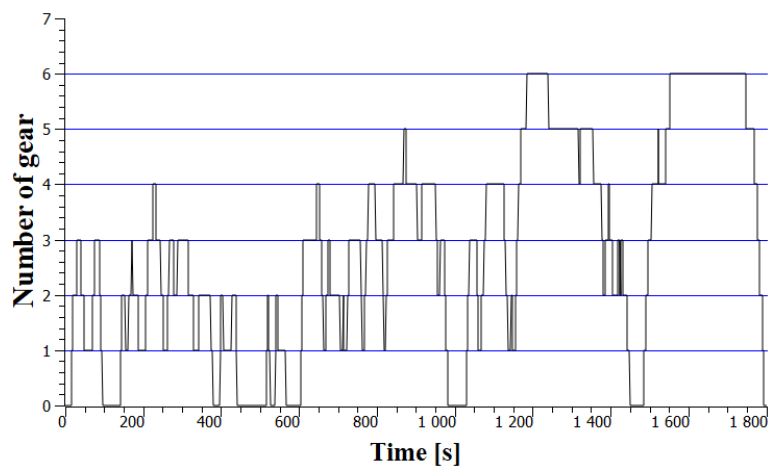

Fig. 6. Calculated gear gearshift strategies

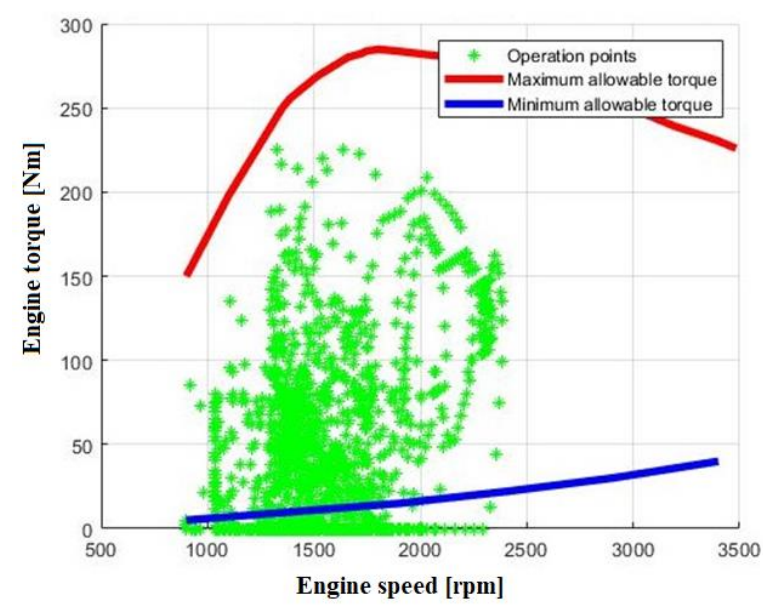

Fig. 7. Calculated engine torque vs. time profile under WLTC $3 b$

In Figure 7 presented covered speed/power region for selected diesel vehicle during WLTC 3b. Moreover, Fig. 7 shows two curves. Red one represents maximum torque curve presented in (Volkswagen, n.d.). Blue one represents minimum available torque that the engine can obtain. Minimum torque curve is a result of the characteristics of the hydraulic dynamometer (The hydraulic dynamometer always is under load conditions, therefore engine cannot obtain a torque under its minimum).

\section{Grid clustering method}

In this step we assume that the OP below minimum torque curve (blue line in Fig. 7) does not taken into account during the calculating phase. Calculation of the weighted operation points was performed with a simple grid clustering approach. There are, many different types of Grid Based Clustering Algorithms (CLIQUE (CLUSTERING IN QUEST), STING (A Statistical Information Grid Approach to spatial Data Mining), Wave Cluster and others) that are described in many scientific works such as [10, $12,20]$ and others. In general, summarizing the information presented in the above publication, the grid-based clustering algorithm has a features described below. A major advantage of this method is fast processing of the data. The computational complexity depends on the number of cells in the spatial area. The basic concept of a grid clustering method is to organize data, by collecting points that falls within prescribed boundaries (rectangular blocks) into groups. The purpose of clustering is to reduce the amount of data being stored while still producing a set of operation points that represent the overall driving cycle.

A simple density based grid clustering algorithm consists of the following calculation steps:

1. Initialization phase: During this phase user defines the grid size as a step along the $\mathrm{X}$ axis and the $\mathrm{Y}$ axis.

2. Creation of the grid structure (The quantized space is divided into predetermined (in first step) number of cells to form grid structure).

3. Calculation of the density (amount of OP) for each cluster in the grid structure.

4. Identifying the average values along $\mathrm{X}$ and $\mathrm{Y}$ axis for each cluster.

5. Selection the operation point (for each cluster) with parameters closest to the average values ( $\mathrm{X}$ and $\mathrm{Y}$ position).

6. Setting the diameter of the OP corresponds to the number of engine operating points in the cluster.

The result of the grid clustering binning is presented in Fig. 8 .

To assess the combustion and emission characteristics in a light-duty diesel engine under WLTC a seven steadystate operating points was chosen (Table 4) in the range of engine operating points (Fig. 8). Note that the variations of torque and engine speed within test matrix are the same of the area were the majority of the operation points lie.

Table 4. Selected operation points

\begin{tabular}{|c|c|c|c|c|}
\hline $\begin{array}{c}\text { OP } \\
\mathrm{N}^{\circ}\end{array}$ & $\begin{array}{c}\text { Engine speed } \\
{[\mathrm{rpm}]}\end{array}$ & $\begin{array}{c}\text { Torque } \\
{[\mathrm{Nm}]}\end{array}$ & $\begin{array}{c}\text { Sampling } \\
\text { frequency } \\
{[\mathrm{kHz}]}\end{array}$ & $\begin{array}{c}\text { Share in } \\
\text { test }[\%]\end{array}$ \\
\hline $\mathrm{p} 1$ & 1315 & 22 & 72 & 14.54 \\
\hline $\mathrm{p} 2$ & 1350 & 56 & 73 & 22.28 \\
\hline $\mathrm{p} 3$ & 1375 & 92 & 75 & 6.8 \\
\hline $\mathrm{p} 4$ & 1650 & 23 & 90 & 13.03 \\
\hline $\mathrm{p} 5$ & 1690 & 71 & 92 & 12.74 \\
\hline $\mathrm{p} 6$ & 1726 & 91 & 94 & 7.74 \\
\hline $\mathrm{p} 7$ & 2280 & 145 & 124 & 5.28 \\
\hline
\end{tabular}




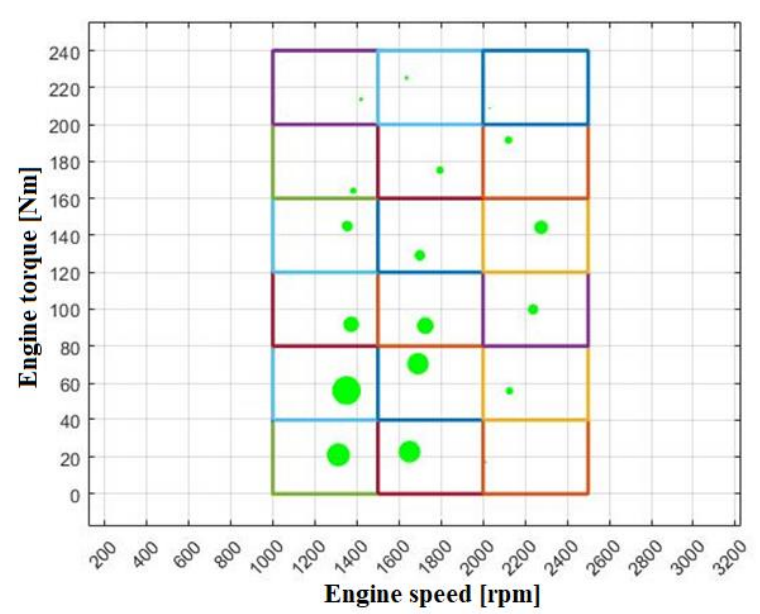

Fig. 8. Binned engine operation points under WLTC $3 \mathrm{~b}$

\section{Experimental setup}

Experiments at seven OP were conducted on a commercial direct injection turbocharged diesel engine AJM 1.9 TDI, made by Volkswagen factory, which is a four stroke, four-cylinder, water-cooled engine. Main characteristics of the base engine are presented in Table 5 .

The schematic diagram of the test bench is showed in Fig. 9. Diesel engine has been properly adapted by SkaTech company to work under dual-fuel mode (diesel fuel and LPG). In this operation mode LPG in gaseous form inducted directly into the inlet manifold to form homogeneous mixtures with intake air. This fuel mixture ignited by the pilot quantity of diesel fuel directly injected in the cylinder. Dual-fuel mode is a proven solution that allows slightly reduce harmful compounds in exhaust gases. Moreover, dual-fuel adaptation is inexpensive and requires minimum installation of additional components. No additional modifications in EGR rate, engine tuning, i.e. injection timing of the pilot fuel and others does not applying.

In-cylinder pressure is acquired with AutoPSI-S fiber optics-based cylinder pressure sensor made by Optrand Inc. The crankshaft position was measured with a digital shaft encoder type CKQH-58 made LIKA. In order to analyze the in-cylinder pressure and net heat release rate the pressure and crankshaft angle data of 150 consecutive cycles are sampled and recorded. Data acquisition were carried out using the module USB-6212 manufactured by National Instruments that was connected to a PC via USB interface. Sampling frequency of data acquisition module for seven OP was calculated according to the Nyquist-Shannon sampling theorem and presented in Table 4. This theorem states that to accurately reconstruct the waveform of the signal the rate of sampling frequency must be greater more than twice the highest frequency of the signal.

In particular, for the continuous measurement of toxic emissions, the exhaust gas analyzer KIGAZ-310 by KIMO was employed. This gas detector used for measuring oxides of nitrogen $\left(\mathrm{NO}_{\mathrm{x}}\right)$, carbon monoxide $(\mathrm{CO})$, carbon dioxide $\left(\mathrm{CO}_{2}\right)$ and oxygen $\left(\mathrm{O}_{2}\right)$ concentration in the exhaust gas.

The net heat release rate (NHRR) is calculated by applying the first law of thermodynamics. The main equation to determine the apparent NHRR for the ICE can be expressed as

$$
\frac{d Q}{d \varphi}=\frac{\gamma}{\gamma-1} \times p \frac{d V_{c}}{d \varphi}+\frac{1}{\gamma-1} \times V_{c} \frac{d p}{d \varphi}
$$

where

$$
\gamma=\frac{\mathrm{C}_{\mathrm{p}}}{\mathrm{C}_{\mathrm{v}}}
$$

The consumption of LPG and diesel fuel are measured by an electronic scales made by AWO firm. All the signals from the measuring devices and instruments were fed to a PC via USB interface.

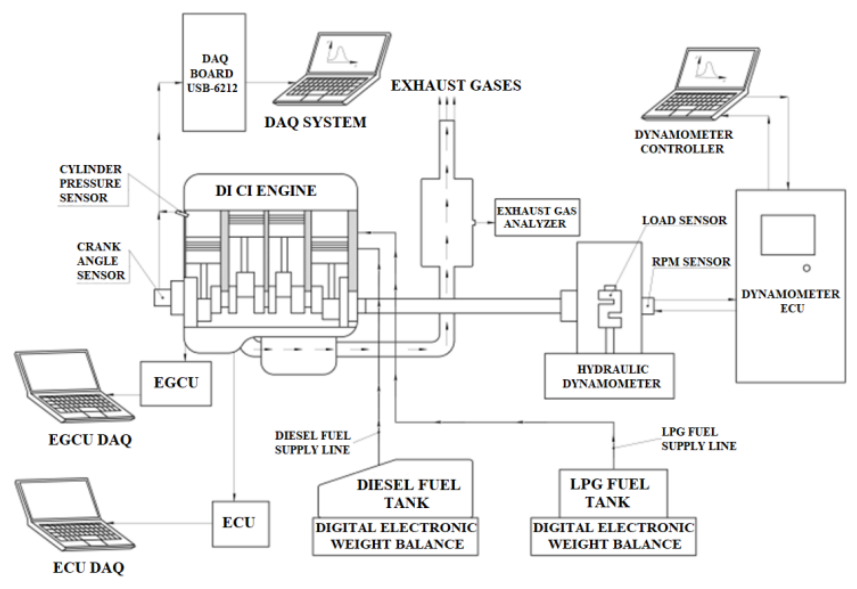

Fig. 9. Test bench schema

Table 5. Base engine specifications

\begin{tabular}{|l|c|c|}
\hline Parameter & Unit & Value \\
\hline Displacement & {$\left[\mathrm{cm}^{3}\right]$} & 1896 \\
\hline Diesel fuel injector type & - & pump and nozzle unit \\
\hline Gas fuel injector type & - & $\begin{array}{c}\text { 4-cylinder LPG/CNG injec- } \\
\text { tion rail BARRACUDA }\end{array}$ \\
\hline Number of cylinders & - & 4 \\
\hline $\begin{array}{l}\text { Number of valves per } \\
\text { cylinder }\end{array}$ & - & 2 \\
\hline Bore & {$[\mathrm{mm}]$} & 79.5 \\
\hline Stroke & {$[\mathrm{mm}]$} & 95.5 \\
\hline Compression ratio & - & $18.0: 1$ \\
\hline Maximum speed & {$[\mathrm{rpm}]$} & 4000 \\
\hline Rated power & {$[\mathrm{kW}]$} & 85 \\
\hline $\begin{array}{l}\text { Maximum torque at } \\
1900 \text { rpm }\end{array}$ & {$[\mathrm{Nm}]$} & 285 \\
\hline
\end{tabular}

The effects of LPG proportion on combustion and emissions under selected OP are investigated. The test fuel is DF100, DF90, DF80 and DF70, which include 0\% LPG, $10 \%$ LPG, $20 \%$ LPG and 30\% LPG on an energy basis respectively. The physic-chemical properties of LPG and diesel fuel are shown in Table 6.

To present the percentage of LPG in the blended fuel on an energy basis, the following equation is used,

$$
\mathrm{SR}=\frac{\dot{\mathrm{m}}_{\mathrm{G}} \times \mathrm{LHV}_{\mathrm{G}}}{\dot{\mathrm{m}}_{\mathrm{D}} \times \mathrm{LHV}_{\mathrm{D}}+\dot{\mathrm{m}}_{\mathrm{G}} \times \mathrm{LHV}_{\mathrm{G}}} \times 100 \%
$$

Increasing gaseous fuel quantity means changing the air fuel ratio. In order to ensure an equivalence engine performance for both the normal diesel mode and the dual-fuel mode AFR must be at the same level (or need to be in this range). Obtaining similar AFR for an engine running in single- or dual-fuel mode required calibrations of the 
EGCU lookup tables. The calibration process is described in sufficient detail in the previous work [14].

AFR was calculated according to simple equation [7]:

$$
\lambda=\frac{21}{21+0_{2}}
$$

where $\mathrm{O}_{2}$ value presented in Fig. 14 .

Table 6. Properties of diesel fuel and LPG [11, 14]

\begin{tabular}{|l|c|c|c|}
\hline Parameter & Unit & Diesel fuel & $\begin{array}{c}\text { LPG }(60 \% \text { butane } \\
\text { and } 40 \% \text { propane })\end{array}$ \\
\hline $\begin{array}{l}\text { Molecular } \\
\text { weight }\end{array}$ & {$[\mathrm{g} / \mathrm{mol}]$} & 96 & $\approx 52.5$ \\
\hline $\begin{array}{l}\text { Liquid density } \\
\text { at } 20^{\circ} \mathrm{C}\end{array}$ & {$\left[\mathrm{kg} / \mathrm{m}^{3}\right]$} & $800-840$ & $\approx 566$ \\
\hline $\begin{array}{l}\text { Vapor pressure } \\
\text { at } 25^{\circ} \mathrm{C}\end{array}$ & {$[\mathrm{bar}]$} & - & $\approx 5$ \\
\hline Cetane number & & $40-55$ & $\approx 4$ \\
\hline $\begin{array}{l}\text { Lower heating } \\
\text { value }\end{array}$ & {$[\mathrm{MJ} / \mathrm{kg}]$} & $\approx 42.91$ & $\approx 46$ \\
\hline $\begin{array}{l}\text { Latent heat of } \\
\text { evaporation }\end{array}$ & {$[\mathrm{kJ} / \mathrm{kg}]$} & 250 & $\approx 405$ \\
\hline $\begin{array}{l}\text { Stoichiometric } \\
\text { air to fuel ratio }\end{array}$ & {$[\mathrm{kg} / \mathrm{kg}]$} & 14.6 & $\approx 15.2$ \\
\hline
\end{tabular}

\section{Results and discussion}

\subsection{The combustion characteristics}

Received pressure data was averaging and calculated pressure curves were positioned as a function of crank angle, the results shown in figure below. The effect of various LPG to diesel fuel blends on in-cylinder pressure and net heat release rate in three OP $(\mathrm{p} 1-1315 \mathrm{rpm}, 22 \mathrm{Nm}, \mathrm{p} 5$ $1690 \mathrm{rpm}, 71 \mathrm{Nm}, \mathrm{p} 7-2280 \mathrm{rpm}, 145 \mathrm{Nm}$ ) are shown in Fig. 10. Note, that all motored pressure traces were measured under zero load conditions. It is clearly seen from Fig. 10 , that the higher LPG percentage produces lower pressure rise rate compared to diesel fuel. This may refer to the reduction in volumetric efficiency, poor in cylinder mixing quality of fuels (LPG to Diesel), an abundant presence of residual gases and incomplete combustion of the fuel mixture.

It is found that the net heat release rate has same tendency as pressure traces and for diesel NHRR is higher than the other LPG/diesel fuel blends. Lower NHRR except the reasons described above, may informs about lowtemperature flames during the combustion. Low temperature leads to a slower reaction rate, which influence on the concentration of $\mathrm{NO}_{\mathrm{x}}, \mathrm{HC}$ and $\mathrm{CO}$ in the exhaust gases. It is also seen that as the load and speed increases, the NHRR increases too. This may refer to a faster reaction rate and better flame propagation with an increase in cylinder pressure.

Furthermore, the reduction in the amount of liquid fuel used to initiate the combustion has adverse effects on the quality of liquid fuel spray. This produces poor liquid fuel preparation and atomization due to a slow development of fine droplets which affects the mixture combustion process [15].
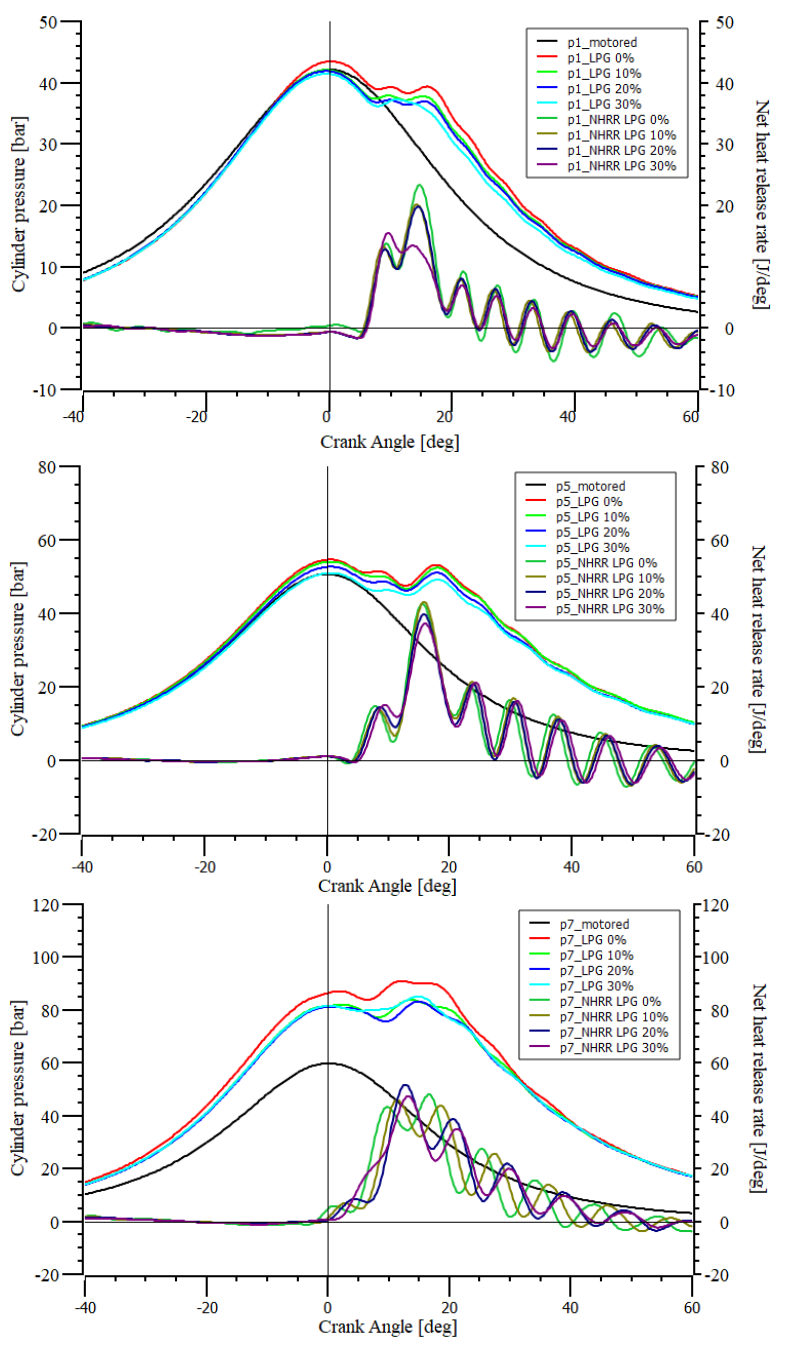

Fig. 10. Cylinder pressure and net heat release rate variations

\subsection{Emission characteristics}

After averaging the emissions data, the results has been presented in figures below. $\mathrm{NO}_{\mathrm{x}}$ is one of the main pollutants emitted by diesel engines, which is toxic and the main precursor to photochemical smog. Nitrogen Oxides $\left(\mathrm{NO}_{\mathrm{x}}\right)$ are products of burning of hydrocarbon fuels under high pressure and temperature conditions in the cylinder. Figure 11 shows the effect of LPG proportion on $\mathrm{NO}_{\mathrm{x}}$ emissions. With the increase of load and engine speed, $\mathrm{NO}_{\mathrm{x}}$ emissions increase too due to the higher in-cylinder temperature. Higher LPG proportion in fuel mixture leads to a simultaneous reduction in $\mathrm{NO}_{\mathrm{x}}$ emissions. The reasons, to explain this can be:

1. As the LPG proportion increases the quantity of fed diesel simultaneously decreases.

2. The temperature drop of the mixture due to heat absorption during LPG vaporization (as a result of higher latent heat value of LPG).

However, temperature drop can lead to incomplete combustion which results in increasing the content of $\mathrm{HC}$ and $\mathrm{CO}$. 


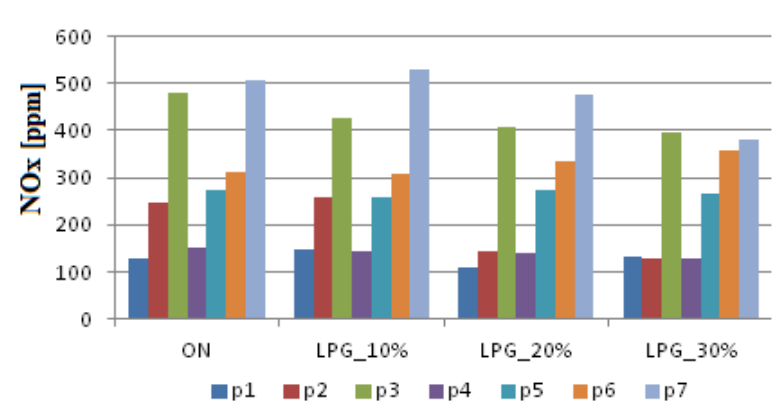

Fig. 11. The comparison of $\mathrm{NO}_{\mathrm{x}}$ emissions

Figures 12 and 13 show comparative values of $\mathrm{CO}$ and $\mathrm{CO}_{2}$ in the exhaust gasses. It can be seen that $\mathrm{CO}$ emissions are higher under dual- fuel mode than those in single- fuel. The main reason is a low cylinder gas temperature due to temperature drop. In addition $\mathrm{CO}$ concentration in exhaust gases possibly increases due to low cetane number of LPG and problems associated with mixing air and gaseous fuel [15]. Carbon monoxide (CO) is a product of incomplete combustion due to limited oxygen supply or an excess of carbon. The higher $\mathrm{CO}$ concentration in exhaust gases can be overcome by varying factors i.e. pilot fuel quantity, injection timing. According to the author [3], the $\mathrm{CO}$ emissions could be reduced with an earlier injection period, which would promote a better rate of $\mathrm{CO}$ emissions decomposition and oxidation. Rise of $\mathrm{CO}$ when the LPG proportion increases is caused by not optimal injection timing for dual fuel mode [9].

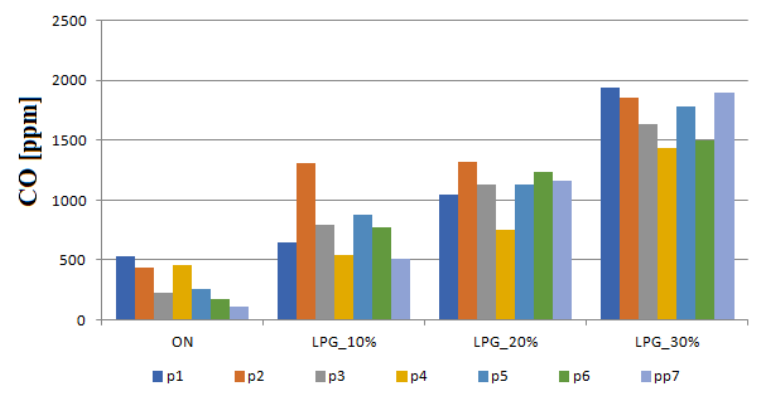

Fig. 12. The comparison of $\mathrm{CO}$ emissions

$\mathrm{CO}_{2}$ as shown in Fig. 13 regardless to LPG proportion is on the same level. This can be explained by the fact that the same AFR (which is confirmed by the content of $\mathrm{O}_{2}$ in exhaust gases shown in Fig. 14) was maintained at all operational points.

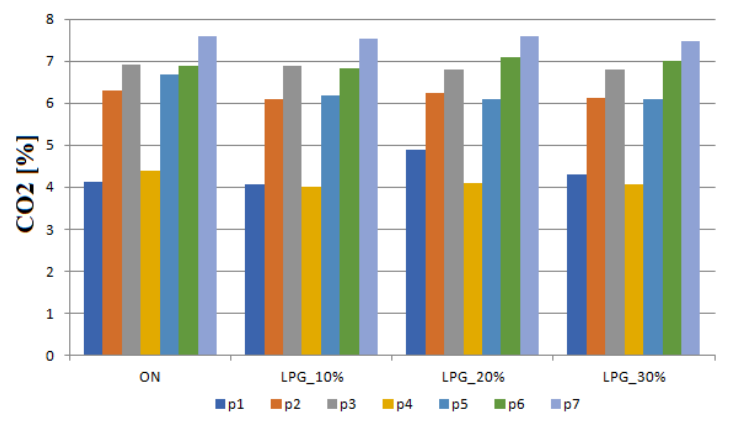

Fig. 13. The comparison of $\mathrm{CO}_{2}$ emissions

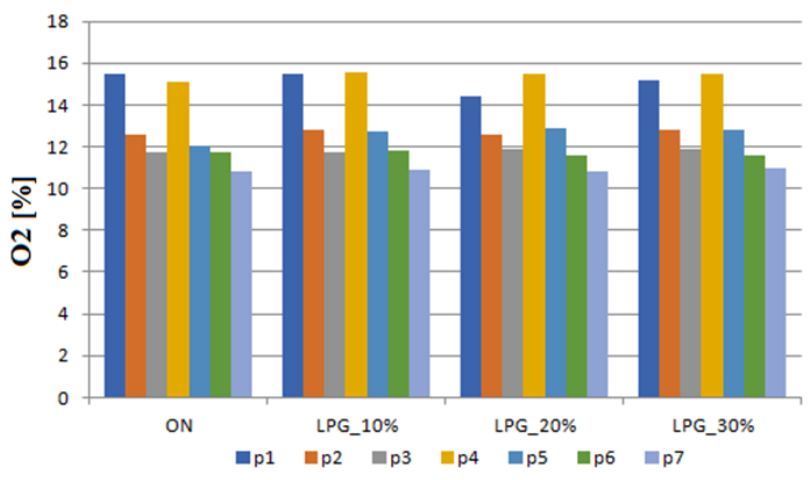

Fig. 14. The comparison of $\mathrm{O}_{2}$ emissions

\section{Summary and conclusions}

The present paper collates the outcomes of a wide research activity devoted to evaluating the effect of various LPG proportion on combustion and emissions under WLTC, in a four-cylinder dual-fuel direct injection turbocharged diesel engine AJM 1.9 TDI. Summing up the paper and the results of the research, the main conclusions drawn are:

1. Back calculate methodology was proposed to estimate engine speed and torque during the WLTC driving cycle. The procedure is based on the simple longitudinal dynamics approach.

2. In order to determine OP's, density based grid clustering method was proposed and implemented.

3. The effects of various LPG proportion on combustion and emissions characteristics reveals that, in the tested operating points, the use of LPG offers a reduction of $\mathrm{NO}_{\mathrm{x}}$ compared to the diesel fuel. The drawbacks concerning to the LPG use are associated with incomplete combustion, lower pressure rise rate with respect to original ones (diesel fuel) and an increment of unburned hydrocarbons that leads to a strong increment of carbon dioxide emissions. In addition by the fact that the AFR in single- and dual-fuel mode was at the same level, $\mathrm{CO}_{2}$ emissions under all OP's are similar.

It seems that LPG dual-fuel combustion mode is a promising technique for controlling $\mathrm{NO}_{\mathrm{x}}$ emissions [1] especially on existing diesel engines with slight modification to the engine structure. Overall, the proper adaptation and optimization of the diesel engine operating conditions including the injection strategy as well as ECU operation algorithms need to be done in order to obtain the improved performance and engine out emissions in dual-fuel operation mode. For Euro 6 and higher engines, the addition of LPG will worsen the emission factors.

The publication focuses on the preparation of a methodology for testing a dual-fuel engine on an engine dynamometer. Although the diesel and LPG fueled engine was tested, the methodology is being prepared for other synthetic fuels that will be used in the future.

\section{Acknowledgements}

The authors wish to express their deep thanks to the SkiTech company (street Franciszka Okroja 22, 80-297 Miszewo) for the LPG fuel supply system. 


\section{Nomenclature}

AFR

DAQ

DF

ECU

EGCU

EGR

FWD

LPG

NEDC

NHRR

OP

PMR

SR

WLTC

WLTP

Af

B

$\mathrm{Cd}$

$\mathrm{C}_{\mathrm{p}}$

Crr

$\mathrm{C}_{\mathrm{v}}$

$\mathrm{d}_{1}$

$\mathrm{d}_{2}$

$\mathrm{Fa}$

Fgrade

$\mathrm{Fi}$

Fr

$\mathrm{Ft}$

Ftr

cles air fuel ratio

data acquisition system

diesel fuel

electronic control unit

electronic gas control unit

exhaust gas recirculation

front wheel drive

liquefied petroleum gas

new European driving cycle

net heat release rate

operation point

power to curb mass ratio

substitution ratio

worldwide harmonized light vehicles test cy-

worldwide harmonized light vehicles test pro-

cedure

cross-sectional area of the vehicle

vehicle width

aerodynamic drag coefficient

specific heat at constant pressure

rolling resistance coefficient

specific heat at constant volume

mass factor of the engine

mass factor of the wheel

aerodynamic resistance

gradient resistance

inertia resistance

rolling resistance

traction force

total traction resistance g gravitational acceleration

h tire height

$\mathrm{H} \quad$ vehicle height

$\mathrm{i}_{0} \quad$ gear ratio of the final drive

$i_{g} \quad$ gear ratio of the transmission for selected gear

$\mathrm{J}_{\mathrm{p}} \quad$ moment of inertia of the rotating components associated with the power unit

$\mathrm{J}_{\mathrm{w}} \quad$ wheel moment of inertia

$\mathrm{L}_{\mathrm{HVG}}, \mathrm{L}_{\mathrm{HVD}}$ lower heating values of gaseous and diesel fuel

$\mathrm{m}_{\mathrm{G}}, \mathrm{m}_{\mathrm{D}} \quad$ mass flow rates of gaseous and diesel fuel

$\mathrm{m}_{\mathrm{i}} \quad$ vehicle mass of inertia

$\mathrm{m}_{\mathrm{v}} \quad$ total mass of the vehicle, represent mass of the base vehicle unit plus driver and all on-board systems associated with the power train system

$\mathrm{N}, \mathrm{N}_{\mathrm{A}}, \mathrm{N}_{\mathrm{C}}, \mathrm{N}_{\mathrm{S}}$ represent the engine, wheel, clutch, propeller shaft, rotating speed respectively

$\mathrm{p} \quad$ in-cylinder pressure

Q total amount of in-cylinder heat

$\mathrm{r} \quad$ rim radius

$r_{d} \quad$ dynamic radius of the tire

$\mathrm{T}_{\mathrm{e}}, \mathrm{T}_{\mathrm{L}}, \mathrm{T}_{\mathrm{tr}}$ represent the engine, powertrain resistance, traction, torques respectively

$\mathrm{Vc} \quad$ in-cylinder volume

$\mathrm{V} \quad$ velocity of the vehicle

$\alpha \quad$ slope angle of the road

$\gamma \quad$ ratio of the specific heats

$\delta \quad$ mass factor

$\eta_{\mathrm{t}} \quad$ driveline overall efficiency

$\lambda \quad$ air fuel ratio

$\rho \quad$ air density

$\varphi \quad$ crank angle

\section{Bibliography}

[1] ASHOK, B., ASHOK DENIS, S., RAMESH KUMAR, C. LPG diesel dual fuel engine - a critical review. Alexandria Engineering Journal. 2015, 54(2), 105-126. https://doi.org/10.1016/j.aej.2015.03.002

[2] DĘBICKI, M. Teoria samochodu: teoria napędu. Wydawnictwa Naukowo-Techniczne, Warszawa 1976.

[3] ECKERT, J.E., SANTICIOLLI, F.M., COSTA, E.S. et al. Vehicle gear shifting co-simulation to optimize performance and fuel consumption in the brazilian standard urban driving cycle. Blucher Engineering Proceedings. 2014, 1(2), 615631. https://doi.org/10.5151/engpro-simea2014-81

[4] GENG, P., CAO, E., TAN, Q. et al. Effects of alternative fuels on the combustion characteristics and emission products from diesel engines: A review. Renewable and Sustainable Energy Reviews. 2017, 71, 523-534.

https://doi.org/10.1016/j.rser.2016.12.080

[5] GIAKOUMIS, E.G., ZACHIOTIS, A.T. Investigation of a Diesel-engined vehicle's performance and emissions during the WLTC driving cycle - comparison with the NEDC. Energies. 2017, 10, 1-19. https://doi.org/10.3390/en10020240

[6] JAZAR, R. Vehicle Dynamics: Theory and Application: Third Edition. Springer. Cham 2017. https://doi.org/10.1007/978-3-319-53441-1

[7] KIMO Kigaz. Combustion gas analyser. User manual. 1-24, 2010.

[8] KROPIWNICKI, J. Modelowanie układów napędowych pojazdów z silnikami spalinowymi. Wydawnictwo AGNI. Pruszcz Gdański 2016.
[9] LUFT, S. A dual-fuel compression ignition engine - distinctive features. Combustion Engines. 2010, 141(2), 33-39. https://doi.org/10.19206/CE-117144

[10] GAN, G., MA, C., WU, J. Data Clustering: Theory, Algorithms, and Applications. ASASIAM Series on Statistics and Applied Probability. 2007. https://doi.org/10.1137/1.9780898718348

[11] MATHWORKS. Vehicle Body 1DOF Longitudinal. Retrieved from

https://www.mathworks.com/help/autoblks/ref/vehiclebody1 doflongitudinal.html

[12] MR, I., MOHAN, D. A survey of grid based clustering algorithms. International Journal of Engineering Science and Technology. 2010, 2, 3441-3446.

[13] PARK, S.H., LEE, C.S. Applicability of dimethyl ether (DME) in a compression ignition engine as an alternative fuel. Energy Conversion and Management. 2014, 86, 848863. https://doi.org/10.1016/j.enconman.2014.06.051

[14] STEPANENKO, D., KNEBA, Z. ECU calibration for gaseous dual fuel supply system in compression ignition engines. Combustion Engines. 2020, 182(3), 33-37.

https://doi.org/10.19206/CE-2020-306

[15] TIRA, H.S., HERREROS, J.M., TSOLAKIS, A. et al. Characteristics of LPG-diesel dual fuelled engine operated with rapeseed methyl ester and gas-to-liquid diesel fuels. Energy. 2012, 47(1), 620-629.

https://doi.org/10.1016/j.energy.2012.09.046 
[16] TUKIMAN, M.M., OSMAN, S.A., FAWZI, M. et al. Effect of performance and exhaust emission using liquid phase LPG sequential injection as an alternative fuel in spark ignition engine. International Journal of Integrated Engineering. 2018, 10(8), 223-230. https://doi.org/10.30880/ijie.2018.10.08.032

[17] UNECE Worldwide Harmonized Light Vehicles Test Procedure (WLTP). 2021.

[18] VOLKSWAGEN. The Self-Study Programme 209 1.9-1tr TDI Engine with pump injection system. Retrived from http://www.volkspage.net/technik/ssp/ssp/SSP_209.pdf
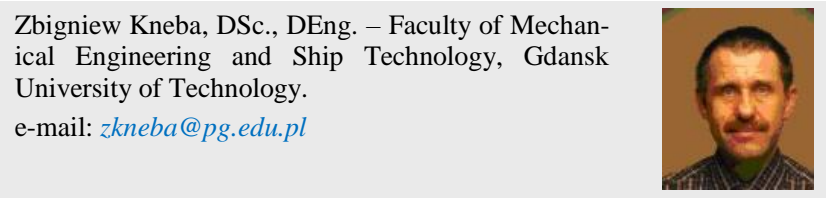

Jacek Rudnicki, DEng. - Faculty of Mechanical Engineering and Ship Technology, Gdansk University of Technology.

e-mail: jacekrud@pg.edu.pl
[19] VWGolf.pl. Dane techniczne Volkswagen Golf 4. Retrived from https://www.vwgolf.pl/dane-techniczne/vw-golf-mk4/

[20] WANG, L., LI, H. Clustering algorithm based on grid and density for data stream. AIP Conference Proceedings. 2017, 1839, 020202. https://doi.org/10.1063/1.4982567

[21] WARCZEK, J. Metoda pomiaru promienia dynamicznego koła samochodowego. Zeszyty Naukowe Politechniki Śląsiej. 2010, 7, 97-103.

Denys Stepanenko, MEng., PhD student - Faculty of Mechanical Engineering and Ship Technology, Gdansk University of Technology.

e-mail: denstepa@pg.edu.pl

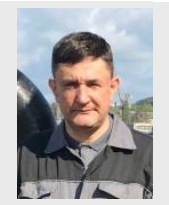

